\title{
Assessment of a Case of Immediate-Type Allergy against Human Insulin in a Type 2 Diabetic Patient and Allergic Reactions to Human Insulin in Japan
}

\author{
Satoko Minakawa ${ }^{*}$, Takahide Kaneko', Tomohisa Fukui1, Yusuke Sakuraba1, \\ Takayuki Aizu1, Ayumi Korekawa1, Noriko Takiyoshi' ${ }^{1}$ Akiko Rokunohe1, \\ Takako Moriyama², Daisuke Sawamura' \\ ${ }^{1}$ Department of Dermatology, Graduate School of Medicine, Hirosaki University, Hirosaki, Japan \\ ${ }^{2}$ Endocrinology and Metabolism, Graduate School of Medicine, Hirosaki University, Hirosaki, Japan \\ Email: ${ }^{*}$ minakawas@yahoo.co.jp
}

Received 12 June 2014; revised 11 July 2014; accepted 10 August 2014

Copyright (C 2014 by authors and Scientific Research Publishing Inc.

This work is licensed under the Creative Commons Attribution International License (CC BY).

http://creativecommons.org/licenses/by/4.0/

\section{(c) (i) Open Access}

\begin{abstract}
We report a 64-year-old female patient with an insulin allergy. She was treated with a combination of oral antihistamines, topical hydrocortisone cream, and moisturizing agents, which resulted in the improvement of eczema and intense pruritus. To evaluate insulin allergy, intradermal skin tests were performed with several insulin agents for clinical use and $0.9 \% \mathrm{NaCl}$. Skin testing with semisynthetic human insulin resulted in local, immediate skin reactions such as itchy erythema and wheals. Furthermore, we analyzed our case and 25 Japanese cases of insulin allergy previously reported in the literature as far as we know. Interestingly, the number of male patients was approximately two times higher than that of female, and the insulin-specific IgE antibody test was positive in 21 patients. We should keep the possibility of human insulin allergy in mind and prepare for it when initiating human insulin therapy.
\end{abstract}

\section{Keywords}

Immediate-Type Allergy, IgE, Intradermal Skin Tests, Human Insulin, Human Insulin Analog

\section{Introduction}

Quality improvements of human insulin used for treating diabetic patients have greatly reduced the incidence of

"Corresponding author.

How to cite this paper: Minakawa, S., et al. (2014) Assessment of a Case of Immediate-Type Allergy against Human Insulin in a Type 2 Diabetic Patient and Allergic Reactions to Human Insulin in Japan. Case Reports in Clinical Medicine, 3, $496-499$. http://dx.doi.org/10.4236/crcm.2014.38108 
insulin allergy, especially at the initiation of insulin therapy [1]. Thus, only a few case reports on immediatetype allergies against human insulin have been published in the literature [1].

\section{Case Report}

A 64-year-old female patient was admitted to our hospital with bronchiectasis and suspected pulmonary infections due to nontuberculous mycobacteria. She was diagnosed with diabetes mellitus based on an elevated plasma glucose level of $544 \mathrm{mg} / \mathrm{dl}$ and a glycated hemoglobin (HbA1c) level of $13.9 \%$. Although she had never been previously treated with insulin, she began treatment with several daily injections of human insulin analogs to attenuate her poor glycemic control. She did not exhibit any anaphylactic reactions or immediate skin reaction such as urticaria.

Despite insulin treatment, her glycemic control deteriorated and she noticed itchy skin wheals at the insulin injection sites, without symptoms of a generalized allergic reaction. Local allergic reactions such as pruritus and erythema developed at her injection sites. The injection sites were rotated to various parts of the abdomen. She consulted our department because of uncontrolled cutaneous symptoms due to insulin allergy. There were itchy erythematous macules of various sizes with crusting at the insulin injection sites on her abdomen (Figure 1(a), Figure 1(b)). We did not observe any insulin lipodystrophic lesions. Taking into account the clinical treatment she had received, we considered immediate-type local allergy against insulin.

To evaluate insulin allergy, intradermal skin tests were performed with human insulin (Humulin R), insulin lispro (Humalog), insulin aspart (NovoRapid), insulin glulisine (Apidra), isophane insulin injection (aqueous suspension, Humulin N), insulin glargine (Lantus), insulin detemir (Levemir), and $0.9 \% \mathrm{NaCl}$. We injected 0.02 $\mathrm{ml}$ of the agents to the left forearm of the patient. Skin testing with semisynthetic human insulin resulted in local immediate skin reactions such as itchy erythema and wheals (Table 1 ).

Although the total IgE $(96 \mathrm{IU} / \mathrm{mL}$ ) was within the normal range $(<232 \mathrm{IU} / \mathrm{mL})$, insulin-specific IgE (measured by a Pharmacia CAP system) was elevated at $74.8 \mathrm{UA} / \mathrm{mL}(<0.34 \mathrm{UA} / \mathrm{mL})$. The total IgG $(1289 \mathrm{mg} / \mathrm{mL})$ was within the normal range ( $870-1700 \mathrm{mg} / \mathrm{dL})$. Unfortunately, total anti-insulin IgG was not assessed. The patient's insulin-binding rate was $76.7 \%$ (normal range $<0.4 \%$ ). The insulin-specific IgE level was high, and almost all human insulin or insulin analogs caused a skin reaction during the skin test. Therefore, we diagnosed her with an insulin allergy.

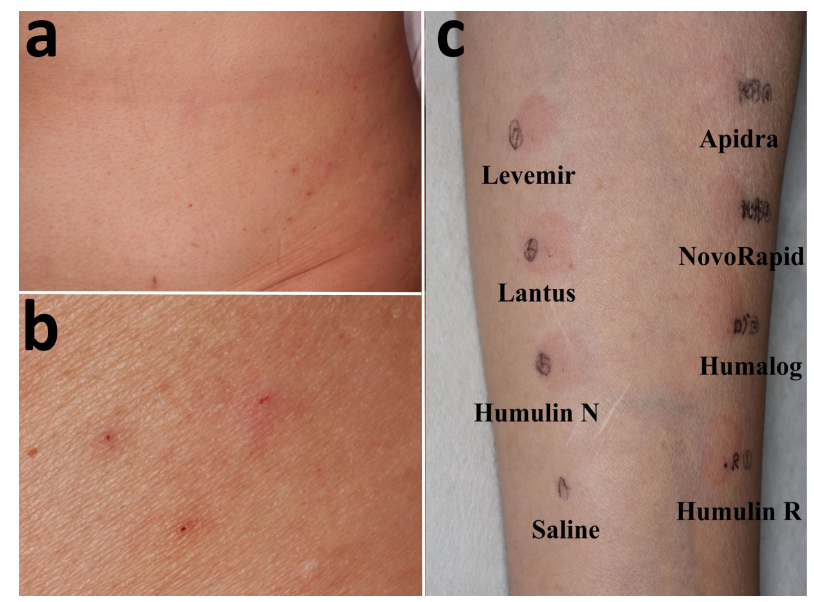

Figure 1. a) There were itchy erythemas of various sizes at the insulin injection sites on the patient's abdomen; b) Magnified view; c) To evaluate insulin allergy, intradermal skin tests were performed with human insulin (Humulin R), insulin lispro (Humalog), insulin aspart (NovoRapid), insulin glulisine (Apidra), isophane insulin injection (aqueous suspension, Humulin $\mathrm{N}$ ), insulin glargine (Lantus), insulin detemir (Levemir), and 0.9\% $\mathrm{NaCl}$ (Saline). Skin test with semisynthetic human insulin resulted in local, immediate skin reactions such as itchy erythema and wheals 30 min after the injection. 
Table 1. Skin tests were performed with several human insulins. Human insulin (Humulin R), insulin lispro (Humalog), insulin aspart (NovoRapid), insulin glulisine (Apidra), isophane insulin injection (aqueous suspension, Humulin N), insulin glargine (Lantus), insulin detemir (Levemir), and $0.9 \% \mathrm{NaCl}$. Skin testing with semisynthetic human insulin resulted in local immediate skin reactions such as itchy erythema and wheals.

\begin{tabular}{cccc}
\hline $\begin{array}{c}\text { Preparations } \\
\text { (trade name) }\end{array}$ & $\begin{array}{c}\text { Erythema (mm) } \\
\mathbf{1 5} \text { min after the test }\end{array}$ & $\begin{array}{c}\text { Wheal (mm) } \\
\mathbf{1 5} \text { min after the test }\end{array}$ & $\begin{array}{c}\text { Erythema (mm) } \\
\mathbf{3 0} \text { min after the test }\end{array}$ \\
\hline $\begin{array}{c}\text { human insulin (Humulin R) } \\
\text { insulin lispro (Humalog) } \\
\text { insulin aspart (NovoRapid) }\end{array}$ & $10 \times 11$ & $0 \times 0$ & $11 \times 10$ \\
insulin glulisine (Apidra) & $8 \times 16$ & $6 \times 9$ & $11 \times 14$ \\
$\begin{array}{c}\text { Isophane insulin injection } \\
\text { (aqueous suspension, Humulin N) }\end{array}$ & $20 \times 15$ & $10 \times 9$ & $12 \times 17$ \\
insulin glargine(Lantus) & $12 \times 10$ & $6 \times 6$ & $10 \times 11$ \\
insulin detemir(Levemir) & $8 \times 10$ & $0 \times 0$ & $12 \times 11$ \\
Normal saline solution & $8 \times 10$ & $0 \times 0$ & $12 \times 10$ \\
\end{tabular}

Since the patient's insulin secretion was preserved, the treatment method was switched to insulin glulisine 4-4-4 and glargine 0-0-0-4 (a total of 24 U/day) to control her hyperglycemia because they caused weaker reactions than the other insulin types. Changing the type of insulin, administering oral antihistamine and topical glucocorticoid, and varying the insulin injection site were effective in treating adverse local reactions. Although she has been satisfied with the reduction in pruritus, she is trying to achieve better blood glucose control because of her HbA1c being 6.6\% after 1 year. We obtained the informed consent from this patient.

\section{Discussion}

Allergy to insulin can manifest as a discrete local dermal reaction, or as a generalized reaction with concurrent local skin reactions. Local symptoms have been described in 5\% - 10\% of insulin treated patients [2], and general symptoms in one series were reported in only $0.07 \%$ ( 4 of 5880 diabetic patients treated with insulin) [3].

To clarify the clinical characteristics associated with insulin allergy, the present case and 25 previous Japanese cases reported in the literature were analyzed based on their clinical course and laboratory results. Our patient noticed itchy skin wheals at the insulin injection sites 6 weeks after starting insulin therapy. Most cases of insulin allergy occur 2 weeks after the initiation of insulin therapy [4]-[6]. In Japan, cases of insulin allergy usually occur within 1 year after the initiation of insulin therapy. However, Matsumura et al. [7] reported the case of diabetes associated with an immediate-type allergy against human insulin 34 months after the initiation of insulin treatment. Most allergic reactions to human insulin are of the local type, but Takuma [6] and Yoshino [8] have both reported cases of generalized allergic reactions.

Since we did not perform intradermal skin tests with insulin preparations containing protamine sulfate; zinc suspension; NPH suspension; and preservative agents such as paraben, cresol, and phenol, the causal substance of the patient's immediate-type allergy could not be identified. However, human insulin, insulin lispro, insulin aspart, insulin glulisine, insulin glargine, and insulin detemir do not contain protamine sulfate, and there is no zinc suspension present in human insulin and insulin glulisine. The local skin allergic reactions and the fact that the insulin specific IgE antibody test was positive highly indicated the presence of a specific allergy to human insulin in this patient.

Various methods have been used in the treatment of insulin allergy, such as oral antihistamines, the addition of glucocorticoids to insulin, desensitization with human insulin [9], continuous subcutaneous insulin infusion [10], and the administration of human insulin analogs in place of human insulin, which have shown to be less allergenic [11]. With the number of the patients with diabetes increasing, the possibility of human insulin allergy should be kept in mind when initiating human insulin therapy.

\section{Acknowledgements}

No potential conflicts of interest relevant to this article were reported. This work was supported in part by 2014 
Hirosaki University Research Support System.

\section{References}

[1] Nagai, Y., Mori, T., Abe, T. and Nomura, G. (2001) Immediate-Type Allergy with Marked Eosinophilia against in Type Human Insulin Associated 2 Diabetic Patient. Endocrine Journal, 48, 311-316. http://dx.doi.org/10.1507/endocrj.48.311

[2] Ganz, M.A., Unterman, T., Roberts, M., Uy, R., Sahgal, S., Samter, M. and Grammer, L.C. (1990) Resistance and Allergy to Recombinant Human Insulin. Journal of Allergy and Clinical Immunology, 86, 45-51. http://dx.doi.org/10.1016/S0091-6749(05)80122-8

[3] Granic, M., Renar, I.P., Metelko, Z. and Skrabalo, Z. (1986) Insulin Allergy. Diabetes Care, 9, 99-100.

[4] Grammer, L.C., Roberts, M., Buchanan, T.A., Fitzsimons, R., Metzger, B.E. and Patterson, R. (1987) Specificity of Immunoglobulin E and Immunoglobulin G against Human (Recombinant DNA) Insulin in Human Insulin Allergy and Resistance. Journal of Laboratory and Clinical Medicine, 109, 141-146.

[5] Balsells, M.C., Corcoy, R.M., Lleonart, R.B., Pujol, R.V., Mauricio, D.P., García, A.P., Pou, J.M. and Cisteró, A.B. (1991) Primary Allergy to Human Insulin in Patient with Gestational Diabetes. Diabetes Care, 14, 423-424.

[6] Takuma, H., Kawagishi, T., Kyogoku, I., Okuno, Y., Nishizawa, Y. and Morii, H. (1995) A Case of Primary and Generalized Allergy to Human Insulin with No History of Any Prior Insulin Exposure. Diabetes Research and Clinical Practice, 30, 69-73. http://dx.doi.org/10.1016/0168-8227(95)01147-1

[7] Matsumura, M., Kawai, K., Watanabe, Y., Tomizawa, H., Nakamura, S., Murayama, Y., Kuzuya, N., Itakura, M., Fujita, T. and Yamashita, K. (1990) A Case of Insulin Allergy Associated with Marked Eosinophilia, High Titer of Insulin Antibodies and Enlargement of Surperficial Lymph Nodes. Journal of the Japan Diabetes Society, 33, 231-235. (in Japanese)

[8] Yoshino, K., Takeda, N., Matsumura, M., Morita, H., Sou, T., Ishizuka, T. and Yasuda, K. (1999) A Case of Diabetes with Systemic Allergy to Human Insulin and Protamine. Journal of the Japan Diabetes Society, 42, 927-930. (in Japanese)

[9] Imakado, S., Hamada, K. and Atsumi, Y. (2009) Subcutaneous Antihistamine Injection Is Effective to Control a Local Allergic Reaction to Human Insulin. Diabetes Research and Clinical Practice, 85, e42-e43. http://dx.doi.org/10.1016/j.diabres.2009.05.013

[10] Nagai, T., Nagai, Y., Tomizawa, T. and Mori, M. (1997) Immediate-Type Human Insulin Allergy Successfully Treated by Continuous Subcutaneous Insulin Infusion. Internal Medicine, 36, 575-578. http://dx.doi.org/10.2169/internalmedicine.36.575

[11] Kumar, D. (1997) Lispro Analog for the Treatment of Generalized Allergy to Human Insulin. Diabetes Care, 20, 13371359. http://dx.doi.org/10.2337/diacare.20.9.1357

\section{Abbreviations}

NPH: neutral protamine Hagedorn. 
Scientific Research Publishing (SCIRP) is one of the largest Open Access journal publishers. It is currently publishing more than 200 open access, online, peer-reviewed journals covering a wide range of academic disciplines. SCIRP serves the worldwide academic communities and contributes to the progress and application of science with its publication.

Other selected journals from SCIRP are listed as below. Submit your manuscript to us via either submit@scirp.org or Online Submission Portal.
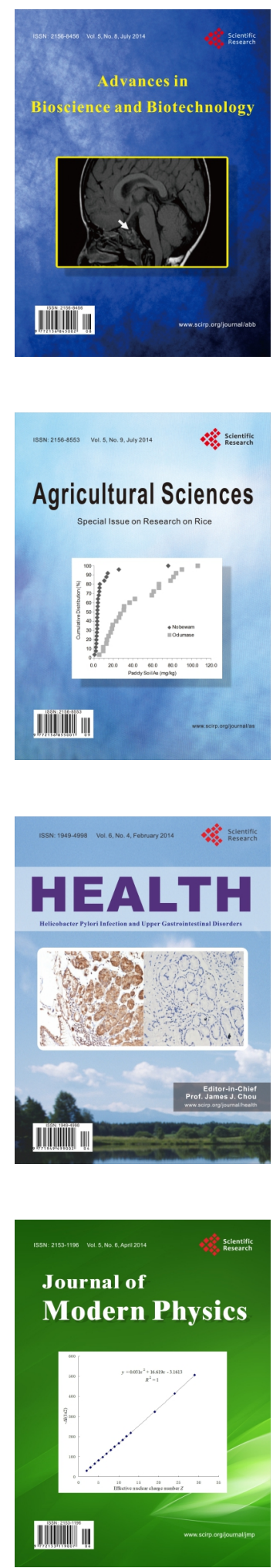
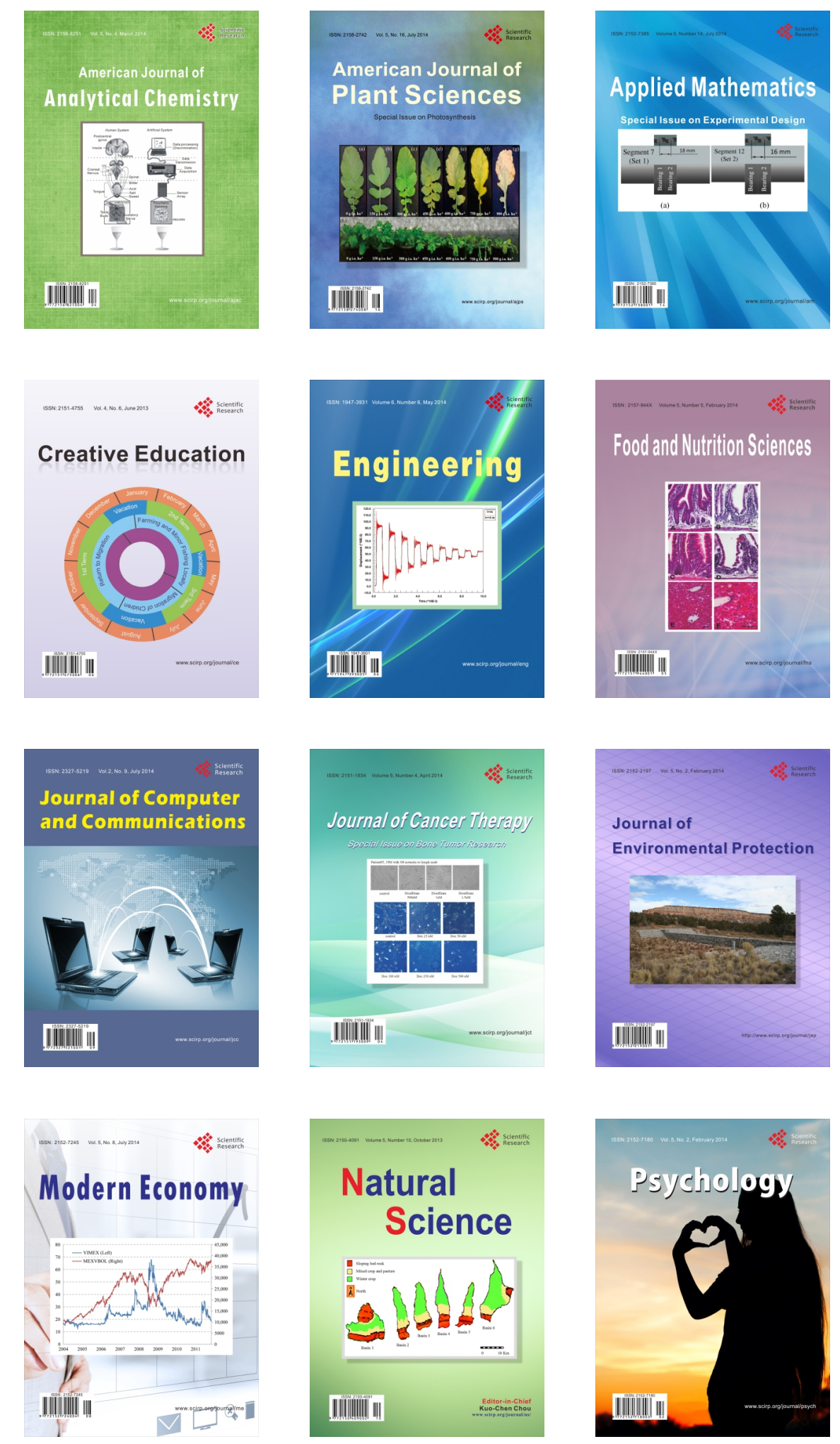